\title{
The discursive construction of teachers and implications for continuing professional development
}

\author{
Ramesh Nair* and Roshayani Arshad \\ Accounting Research Institute, Universiti Teknologi MARA, Shah Alam, Selangor, Malaysia
}

\begin{abstract}
The Malaysia Education Blueprint 2013-2025 is a document that spells out a plan of action for revamping the Malaysian education system. Therefore, it is no surprise that references are made to teachers and their role in ensuring the successful execution of the action plan. Although the blueprint does not set out a course of action for teachers of individual subjects, specific reference is made to English language teachers and this is ideologically significant. In order to understand this significance and how the blueprint positions Malaysian English language teachers, the document needs to be located within the wider discourse community, vis-à-vis through an intertextual reading. In this paper, we first examine the discursive construction of English language teachers in the blueprint as well as media texts to illustrate how these texts have collectively constructed the identity of Malaysian English language teachers. Next, we argue that this discursive construction of Malaysian English language teachers has had consequences for the way continuing professional development programmes have been organised for them in the first of three waves of the Malaysian Education Blueprint action plan from 2013 to 2015. The findings reveal that continuing professional development programmes during this period have focused predominantly on the training of the discursively constructed inept Malaysian English language teacher to ensure they possess the desired proficiency and are able to make changes to existing classroom practices that are aligned with the government agenda.
\end{abstract}

Keywords: discursive construction; intertextuality; continuing professional development; English language teachers

$\begin{array}{cc}\text { First Received: } & \text { Revised: } \\ 1 \text { April } 2017 & \text { 9 January 2018 }\end{array}$

Final Proof Received: 26 May 2018

\section{Accepted: \\ 9 March 2018}

Published:

31 May 2018

How to cite (in APA style):

Nair, R. \& Arshad, R. (2018). The discursive construction of teachers and implications for continuing professional development. Indonesian Journal of Applied Linguistics, 8(1), pp. 131-138. doi: 10.17509/ijal.v8i1.11472

\section{INTRODUCTION}

It is difficult to accurately point to a specific time in history when the standard of English began to decline in Malaysia. Nevertheless, after independence from the British, the switch in the medium of instruction at schools from English to Bahasa Malaysia, the country's national language, certainly contributed to this decline (Tsui, Shum, Wong, Tse, \& Ki, 1999). During the 1970s and 80s, the English language was often juxtaposed with Bahasa Malaysia in mainstream narratives, often for political mileage. Debates on the issue alluded to the idea that giving too much prominence to English within the education system would likely jeopardise the position of Bahasa Malaysia. Indeed, language education policies have always been highly politicised in multiracial Malaysia (Tan, 2005), and this is to be expected to some extent given the fact that language and identity are strongly intertwined.

The 1990s gave way to increased dialogue about the declining standard of English among Malaysians. Discourse in government-owned mainstream media during this time strongly suggested that mastery of the

\footnotetext{
* Corresponding author:

Email: ramesh@salam.uitm.edu.my
} 
English language was an important prerequisite for the nation's development. Among the various reasons given to support this assertion was the fact that Malaysia's private sector operates in the English language and a workforce competent in English is an important pull factor for foreign investment (Gill, 2012). Alongside narratives about the importance of English were media reports about students who were unable to cope with English language communication in the real world despite having received formal instruction in the language at both primary and secondary schools (Musa, Koo, \& Azman, 2012). Such reports about poor English language proficiency among Malaysians led to increased public scrutiny over the teaching of English at schools.

\section{Negotiating the Declining Standard of English Language Education}

In the 21st century, the declining standard of English remains a major concern in Malaysia. However, recent attempts to accord greater prominence to the language have been thwarted either by fears that giving greater importance to English would undermine the status of the Malay language or by concerns that policy changes granting prominence to English at schools would disadvantage certain quarters of society, particularly the rural Malays. As a result, policies related to English language use have either been short-lived, or not come to fruition altogether. For example, a policy decision that made English the medium of instruction for the teaching of Science and Mathematics at primary and secondary schools was enforced in 2003 but revoked less than a decade later (Ha, Kho, Chng, 2013). While initial reports indicated that both students and teachers were managing with the change in the medium of instruction, it was later deemed to be detrimental to the academic performance of students in rural parts of the country. In 2013, an announcement was made by the Minister of Education that passing English would be a compulsory requirement for students to attain a high school certificate after 2016 (Hanewald, 2016). It was later announced that this plan would be delayed indefinitely to provide both students and teachers with more time to work towards meeting this requirement.

Despite revocations and reversals in decision, the commitment for change to ensure that students leaving Malaysian schools are proficient in English remains the same, and this is clearly outlined in the Malaysia Education Blueprint 2013-2025, a document that spells out the direction Malaysia plans to take to reform its education system.

\section{Teacher Identity and Professional Development}

English language teachers have been at the centre of various debates about English language education in Malaysia in recent times, and this is to be expected given the fact that the responsibility of teaching English lies with teachers. It is in these debates that we find the discursive construction of Malaysian English language teachers. This paper is grounded in the assertion that the identity construction of English language teachers through mainstream discourse has helped shape how professional development programmes are designed for them.

The importance of understanding how identities of teachers are constructed through language use in texts is reflected in several studies. In Hong Kong, Trent (2012) examined the discursive positioning of native-speaking English teachers and explained how this had broader implications for changes in the education system and school culture. Ha and Que (2006) explored the discursive construction of shared identity among Vietnamese English language teachers as they negotiated issues of morality during language lessons. The findings revealed that the teachers had a greater sense of ownership of English as an International Language by approaching their lessons from a uniquely Vietnamese approach that emphasised overt instructions in morality. In Brazil, de Figueiredo (2017) examined the discourse of English teachers to understand how wider narratives about the English language in the public domain are internalised and reproduced by teachers based on their own experiences of teaching the language. These studies provide evidence of the power of discourse in shaping the professional realm for teachers.

Attempts to understand the reasons behind the falling standard of English continue to be an important area of scholarship in Malaysia; however, studies have focused primarily on the complexities of language policies as well as classroom practices (Gill, 2012). Relatively fewer studies have focused on the professional development of Malaysian English language teachers. Bowden (2015) for example, looked at an English language teacher development programme in which native speaker teachers supported Malaysian teachers of English while Nambiar and Thang (2016) reported how the use of online blogs promoted reflective practices and facilitated the professional development of English language teachers. While such studies play an important role in assessing and proposing improvements for on-going continuing professional development programmes, they do not provide insights into factors that shape the nature of such professional development programmes. The present study therefore attends to this gap by examining how the discursive construction of Malaysian English language teachers in policy documents as well as in the media has shaped professional development programmes for teachers in the country.

Before examining how language is used to discursively construct the identity of Malaysian English language teachers, the following section elaborates on a framework developed by Grundy and Robinson (2004, cited in Sachs, 2007), and further advanced by Sachs (2007) for understanding the continuing professional development (CPD) of teachers. This framework elucidates the various forms that CPD programmes take, and supports the notion that the selection of a particular 
CPD approach is based on assumptions about the needs and capabilities of the teachers involved (Evans, 2014).

\section{Approaches to Continuing Professional Development of Teachers}

Kennedy (2005) asserts that there are a variety of CPD models that explain the potential of CPD initiatives for transforming practices and promoting professional autonomy. While such models provide a framework suitable for understanding the various purposes of CPD programmes, we draw on them to illustrate how the perceived identity of potential programme participants predetermines the nature of CPD programmes. Specifically, we attempt to show how the identity construction of Malaysian English teachers in policy documents as well as media texts has contributed in shaping the nature of CPD initiatives designed for them. Towards this end, we rely on a framework offered by Sachs (2007) to define four approaches that may be taken in developing CPD programmes, namely, retooling, remodelling, revitalising, and re-imagining.

The first of the four approaches is retooling which positions teachers as part of a larger organisation in which they need to be accountable and adhere to standards prescribed in education policies (Sachs, 2007). The assumption of this approach is that CPD programmes should equip teachers with the skills needed to improve their classroom practices. The second of the four approaches is remodelling that views teachers as performers whose role is to engage with students and ensure that classroom practices conform to agendas for change proposed by authorities. Teachers, therefore, return to classrooms after CPD programmes to carry out tasks for which they have been trained. The third approach to CPD of teachers is revitalising which stresses the importance of connecting teachers and focuses on teacher learning based on the practice of rethinking and reviewing existing practices so that teachers become reflective practitioners. This approach proposes that members of a community work together and maintain control over a commonly agreed upon agenda (Sachs, 2007). In addition to these three approaches that Sachs (2007) drew from Grundy and Robison (2004, cited in Sachs, 2007), re-imagining was added as a fourth approach. This is an approach that positions teachers as "shapers, promoters and wellinformed critics" of reform (Sachs, 2007). This approach envisions teachers as active participants in CPD programmes where they engage in dialogue and are part of the thinking and planning process before strategies are implemented in classrooms.

Clearly, each approach positions teachers slightly differently. Broadly speaking, CPD initiatives are designed along a continuum where teachers are passive recipients of knowledge at one end and active participants at the other. The method of analysis explained in the following section reveals how the perceived identity of teachers contributes to positioning them along this continuum.

\section{METHOD}

Examining the discursive construction of identity should involve critical reading of multiple texts in which those identities are positioned. This critical reading draws upon intertextuality, that is, the idea that a text is shaped by other texts rather than existing in isolation (Fairclough, 1992; Johnson, 2015).

Texts are drawn from other texts through manifest intertextuality and constitutive intertextuality. The former refers to the practice of taking direct quotes from previous texts while the latter refers to the transposing of parts of earlier texts and making them appropriate for a target readership (Fairclough, 1992). As new texts draw from existing texts, narratives of the dominant class could either become further entrenched or could even be contested. Ultimately, these narratives collectively contribute to the meaning-making process that shapes reality for the consumers of texts (Fairclough, 2003).

The aim of this paper is to illustrate how narratives containing elements of manifest and constitutive intertextuality have collectively shaped the identity of Malaysian English language teachers. The texts selected for analysis were anchored to several news reports that appeared in September 2013. These reports quoted the then Education Minister II Datuk Seri Idris Jusoh who described English teachers in the country as "incapable" and "unfit." As this remark was tied to a dialogue session he participated in about the National Education Blueprint 2013-2025, references made to English education in the blueprint were also analysed. Next, a series of newspaper articles predating as well as following the remarks by the Minister in September 2013 were collected and analysed for evidence of how manifest and constitutive intertextuality collectively shaped a public image of Malaysian English language teachers at a point in time when significant changes were being planned for English language education in Malaysia through the National Education Blueprint 2013-2025.

The newspaper articles were extracted from online news portals, specifically those of The Star, The New Straits Times, The Malay Mail, The Malaysian Insider, and The Borneo Post. A search for keywords such as "MEB," "English Language Teachers," "standards in English," "English teachers," "Malaysia Education Blueprint," and "English lessons" was carried out at every online news portal. The search involved looking for these words and phrases either in isolation or in combination with one another. Once the articles were extracted, all clauses that made references to English language teachers were separated. The aim of this analysis is to unpack the representation of collective identity for Malaysian English language teachers. To do this, Halliday's (1985) systemic linguistics was drawn upon to reveal how teachers were placed within transitivity schemes. Transitivity is often drawn upon in critical linguistics as it explains how actors are positioned within clause structures to code happenings in ideologically significant ways (Fairclough, 2001). 
In the following section, the analysis is followed by a discussion that relates to how this collective identity has dictated the approach taken in CPD programmes designed for English language teachers in the country.

\section{FINDINGS AND DISCUSSION}

The launch of the Malaysia Education Blueprint 20132025 (MEB) in September 2013 was followed by extensive media coverage about the future of Malaysia's education system. The MEB is essentially an action plan for revamping the Malaysian education system to ensure that the next generation of Malaysians remains competitive in a globalised world. Towards this end, the document calls for 11 shifts that need to take place within the education system. These shifts have to do with changes in "strategy and direction," as well as "operational changes" that differ greatly from current practices (Malaysia Education Blueprint, 2013, p.E9).

The second of the 11 shifts foregrounds the teaching of languages and calls to "ensure every child is proficient in Bahasa Malaysia and English language" (p.E9). Given the fact that the blueprint does not make references to the various subjects taught at schools, the specific reference made to the teaching of languages, particularly English, is ideologically significant. It reflects the importance of English as a subject as well as concerns about the current teaching and learning of the language. Beyond this, it may be argued that the blueprint attempts to isolate a problem as the second shift refers to an aspiration that has yet to be realised; students lack proficiency in English.

The launch of the blueprint was followed by extensive media reports, and several focused on English language education in Malaysia. Much of what was reported in the media about the state of English language education as well as specific references to Malaysian English language teachers was shaped by two key texts. These were the MEB policy document itself and a press conference by the Minister of Education II soon after the official launch of the MEB.

An examination of the press articles collected from the various online news portals revealed that the news articles were anchored to a remark made by the Minister of Education II soon after the launch of the MEB. At the press conference, the Minister reported on the performance of English language teachers in the Cambridge English Placement Test, a proficiency test conducted in 2012 as part of a baseline study that went on to inform the blueprint:

About two-thirds of English Language teachers in the country have been classified as "incapable" or "unfit" to teach the subject in schools. Education Minister II Datuk Seri Idris Jusoh said such teachers had been sent for courses to improve their proficiency in the language.

"The ministry will also consider sending them overseas for exchange programmes to take up TESL (Teaching of English as a Second Language) courses, " he said during a dialogue session on the National Education Blueprint 2013-2025 held at the Karangkraf headquarters here yesterday.

(The Star Online, September 11, 2013)

The Cambridge English Placement Test is benchmarked against the Common European Framework of Reference for Languages (CEFR). The baseline study was reported based on the assumption that English language teachers in Malaysia should achieve a reference level of $\mathrm{C} 1$ which reflects users who are able to produce "fluent, spontaneous communication" (North, 2008, p. 35). Teachers who scored below the desired $\mathrm{C} 1$ band were the ones described as unfit. The above statement by the Minister was made at a major event held to disseminate information about the MEB, and was therefore picked up and published by all major news portals in the country. The statement about unfit English language teachers by a minister served as a catalyst for a series of narratives that tied the problem of falling standards in English in the country to incompetent English language teachers. The teachers were effectively isolated as the source of the problem, and the blueprint was constructed as the solution to the problem.

Several news texts published soon after the launch of the MEB and the statement by the minister are reproduced here to illustrate how one text informed another through both manifest and constitutive intertextuality, and in so doing, discursively constructed a collective identity of Malaysian English language teachers.

The Star Online, September 11, 2013

E1

About two-thirds of English Language teachers in the country have been classified as "incapable" or "unfit" to teach the subject in schools.

E2

About $70 \%$ out of the 60,000 English Language teachers, who sat for the English Language Cambridge Placement Test, performed poorly.

\section{The New Straits Times, September 12, 2013}

E3

"This is because we only want teachers who are really qualified to teach the language in schools. They must be really qualified. ...

\section{Borneo Post Online, September 14, 2013 \\ E4}

... these English language teachers, classified as "unfit" to teach the subject, had been sent to courses to improve their command of English. ...

Excerpts E1 to E4 all provide evidence of manifest intertextuality as direct quotations of the minister are used in the various newspaper reports to offer a link to the original discourse. Further, the direct quote in excerpt E3, reveals an attempt to create an Us versus Them divide. In E3, the minister uses the pronoun "we" 
to position the dominant class and the public at large against "they," the teachers whose qualifications to teach English is now questionable.

Picking up on the minister's comments and earlier news reports such as E1 to E4 listed above, an editorial in The Malay Mail a few days later offered scathing remarks about English language teachers:

\section{The Malay Mail Online, September 16, 2013} E5

... . Recently we heard that out of 60,000 English teachers nationwide, about 70 per cent of them did poorly when sitting for the English Language Cambridge Placement Test. ...

E6

...these "unfit" teachers have no business teaching English in the first place. If they are unfit to teach English to our kids and have to be trained further to be good enough, how is it that they became English teachers in the first place? ...

E7

... . The fact that such a large proportion of our English teachers are so poor at what they are supposed to teach speaks poorly of the entire teacher selection process. ...

E8

...if so many of our teachers are not up to mark, is it worth all that money to send all of them to courses and exchange programmes overseas? ...

E9

... . If they were not qualified to teach English in the first place, why bother training them further? ... E10

... . Would it not be more cost-effective to slowly cut away the deadweight and instead use the ministry's resources to hire better, more competent people who do not require extensive, expensive training just to be able to do their jobs properly? ... E11

... . Continuing with "retraining" for so many teachers who weren't meant to be hired as English teachers in the first place is like throwing good money after bad. ...

This editorial provides evidence of constitutive intertextuality as the writer picks up words and phrases from earlier narratives such as "unfit" and then further reinforces the idea with new lexical units such as "deadweight" in reference to the allegedly unfit teachers.

The editorial also maintains a strong Us versus Them divide as the writer creates solidarity with readers through the use of inclusive pronouns as such "we" (E5) "our kids" (E6) and "our teachers" (E8), and distances the teachers through the process of Othering by using excluding pronouns such as "they" and "them" throughout the editorial. Othering is essentially a process of excluding and even discriminating often achieved in texts through the use of linguistic devices (Scheibelhofer, 2017). This attempt at Othering is taken further in the editorial by objectifying the teachers and making them recipients of verbs such as "cut away" (E10). The editorial also makes use of rhetorical questions as illustrated in excerpts E8 to E10. These questions serve a persuasive end (Labrador, Ramón, Alaiz-Moretón, \& Sanjurjo-González, 2014) as readers of the texts are convinced to buy into the embedded assertion that spending money on training teachers who failed to achieve the desired $\mathrm{C} 1$ band is a waste of money. This assertion is then further reinforced in E11 where the writer draws on constitutive intertextuality to draw attention to the planned retraining of trained English teachers which he asserts is not financially viable.

Already, the announcement by the minister, the news reports quoting him and the editorial that followed are seen to shape a collective identity of Malaysia English language teachers as inept at teaching English. However, the construction of this collective identity should not be read in isolation as they, in fact, reinforce earlier narratives that even preceded the launch of the blueprint and the announcement by the Minister. Earlier media texts, in fact, set the backdrop and formed a schema that further shaped the identity of English language teachers in Malaysia after the launch of the blueprint and the minster's announcement. Excerpts E12 to E 16 illustrate this point:

\section{Borneo Post Online, September 11, 2011}

E12

Foreign English language experts and consultants are already moving around primary schools in town, helping local teachers elevate the standard of English.

\section{The New Straits Times, September 19, 2011}

\section{E13}

... many English teachers were not proficient enough and this had a domino effect on the students.

\section{The New Straits Times, November 11, 2011}

E14

Many people blame the lack of proficiency among students on English teachers and the system, but how many know that there are many English teachers out there who are proficient in English but lack pedagogical skills?

\section{The Star, May 2, 2012}

E15

The quality of teachers and schools has fallen steadily. This is reflected in the poor quality of those who leave school ...

\section{The Star Online, February 27, 2013}

\section{E16}

$\ldots$ it is alarming to notice that there are some young English Language teachers who are not capable of holding their own ... 
The examples above, from excerpts E12 to E16, show narratives that suggest Malaysian English language teacher lack competence. The specific reference to the English language subject in the blueprint is therefore not random. Rather, it draws on past narratives that have highlighted the declining standard of English in Malaysia, and have placed the blame for this on the quality of teachers. Indeed, read intertextually, the Minister's comment about unfit teachers was fed, to some extent at least, by earlier narratives in the public sphere.

In E12, Malaysian teachers are made recipients of help from "Foreign English language experts and consultants" as they are positioned in the weaker object position within the clause (Halliday, 1985). Both E13 and E15 contain clauses of the relational process (see Halliday, 1985) that serve to highlight the character of the teachers. In both these excerpts, Malaysian teachers are described as individuals who "lack proficiency" and whose quality has fallen; they are hence directly responsible for students who have failed to master the English language. Excerpt E14 again draws on the use of rhetorical questioning to persuade readers that even when teachers are proficient in English, another concern is their lack of pedagogical content knowledge. Finally, in E16, we see another relational process clause that describes young English language teachers as unable to manage their responsibilities. In isolation, these clause structures may not appear to have much impact on the shaping of identity. However, these structures work collectively to construct a single identity for Malaysian English language teachers.

In all the excerpts above, there is evidence of Othering as we see how Malaysian English language teachers are distanced from major stakeholders in English Language Education such as the Minister of Education, the Ministry of Education, and parents. In all instances, readers are positioned to see the issue of declining standards as one that needs to be blamed on inept Malaysian English language teachers.

The distance created through the process of Othering and the further disempowering of English language teachers within clause structures in mainstream narratives has helped create the idea that these are teachers in dire need of help. It is this identity that has to a great extent shaped the nature of professional development programmes offered to Malaysian English language teachers.

At this point, we return to Sachs' (2007) framework that proposes the four approaches to CPD. Matched against this framework, the nature of CPD programmes for Malaysian English teachers have largely been confined to the retooling and remodelling approaches. The aim of CPD programmes in Malaysia has primarily been to equip teachers with skills that are necessary to help them deliver lessons effectively, and this has been because mainstream narratives, such as those illustrated earlier, have alluded to the fact that teachers lacked the proficiency and skills necessary to teach English effectively. Examples of CPD programmes that have been carried out in recent times have included the English Native Speaker Mentoring programme that saw native speaker teachers mentoring Malaysian English language teachers (English Native Speaker Programme a Success, January 31, 2015). Later, the Professional Upskilling of English Language Teachers programme was introduced with the aim of raising the proficiency level of primary and secondary school teachers as measured against the CEFR (Ali, 2016). Addressing past narratives about English teachers who were not competent, these two professional development programmes were introduced to provide support. They typify CPD programmes that draw on the retooling approach to ensure that teachers are equipped with the knowledge and skills necessary to adhere to standards prescribed in education policies (Sachs, 2007). The aforementioned programmes address national concerns that Malaysian English teachers did not meet minimum standards in terms of proficiency and pedagogical content knowledge to teach effectively.

Several programmes also emerged at schools soon after the launch of the blueprint to address the proposed second shift calling for students to be proficient in English. As these programmes took off, so did new CPD initiatives. These were CPD programmes that drew on the remodelling approach, designed to ensure that teachers were trained to conform to agendas for change proposed by authorities (Sachs, 2007). For example, the OPS-English programme was launched as an initiative to help students in lower secondary classes gain confidence in speaking English. To ensure the successful execution of this programme, teachers underwent training through CPD programmes which provided them with step by step instructions on how to carry out classroom activities. During these types of CPD programmes, teachers take on the role of passive recipients of instruction and information. They are required to have a clear understanding of what was required of them, then return to classrooms and carry out lessons as instructed.

In comparison to CPDs that adhered to the retooling and remodelling approaches, CPD programmes conforming to the revitalising and reimagining approaches have been significantly fewer. There has been some evidence of CPD programmes moving towards a revitalising approach with the appointment of experienced and highly qualified Malaysian English teachers as School Improvement Specialist Coaches. These coaches, also referred to as SISC+, are teachers who have been taken out from schools and placed under the purview of district education offices. They are assigned to set up communities of practice within and across schools in a district and support teachers through mentoring programmes that draw on lifelong learning and collaborative practices (Ansawi \& Pang, 2017). Although the setting up of these communities of practice contributes towards teacher development, it may be argued that the labeling of experienced teachers as School Improvement Specialist Coaches is in itself an 
act of Othering. Separating these experienced English teachers and calling them by another name only serves to once again position the remaining English teachers as less than qualified recipients of instruction from these coaches.

The approaches of revitalising and re-imagining, as proposed by Sachs (2007), call for teachers to be empowered and in control of their CPD. Ideally, teachers at schools should be initiating the set up of their own communities of practice where they maintain control and determine their own professional agenda. To some extent at least, the introduction of an SISC+ to manage this has diminished the opportunity for teachers to independently shape and promote reform as proposed through the re-imagining approach (Sachs, 2007).

\section{CONCLUSION}

The MEB makes direct references to CPD and proposes reducing the administrative burden faced by Malaysian teachers so that they are able to develop and disseminate new knowledge as part of their professional development journey (Anderson, Young, Blanch \& Smith, 2015). While this is highly desired, there is a need to critically reflect on the nature of CPD programmes available for Malaysian English language teachers. To what extent are teachers seen as disseminators of knowledge at CPD programmes? While there have been studies in the past that have examined CPD programmes in Malaysia (Bowden, 2015; Nambiar \& Thang, 2016), none have attempted to reflect on factors that shape the nature of $\mathrm{CPD}$ programmes. Past studies have also not critically evaluated the nature of CPD programmes against an existing framework such as the one offered by Sachs (2007). The analysis undertaken in this paper has therefore been a departure from previous studies in that it reveals how the wider discourse community has shaped the identity of Malaysian English language teachers and this, in turn, has limited CPD programmes to those of retooling and remodelling.

The analysis has revealed that the MEB, the statement by the minister, and even narratives predating the launch of the MEB have all collectively constructed an image of inept Malaysian English language teachers. This was achieved through language use, specifically the repeated use of adjectives such as "unfit" and other synonymous words and phrases to describe English teachers. Further studies should examine how Malaysian English language teachers themselves construct their identity through personal and professional narratives. Such studies may help determine how teachers contest or even facilitate the identification of the inept Malaysian English language teacher.

It appears that absence of alternative narratives that foreground good English teachers and quality classroom practices has resulted in CPD programmes that are confined to the approaches of retooling and remodelling. There needs to be a concerted effort at developing CPD programmes that draw on the reimagining approach proposed by Sachs (2007) to recognise the active role teachers should rightfully play in CPD programmes. Experienced teachers possess a wealth of knowledge that remains largely tacit. This is the knowledge that should be tapped through CPD programmes so that teachers view these programmes as an opportunity to share their knowledge and expertise (Patton, Parker, \& Tannehill, 2015). CPD programmes must also serve to empower teachers and shape a positive attitude towards teaching and learning (de Vries, Jansen, \& van de Grift, 2013). CPD initiatives in the country that are tied closely to the retooling and remodelling approaches do indeed play an important role in enhancing the quality of English language education in the country; however, alternative programmes that draw on the revitalising and reimagining approaches are also necessary to ensure that English language teachers are not always left at the very end of the knowledge dissemination chain.

\section{REFERENCES}

Ali, H. M. M. (2016, April 24). Tips to upskill English teachers. The Star Online. Retrieved from http://www.thestar.com.my/news/education/2016/0 4/24/tips-to-upskill-english-teachers/

Anderson, V. R., Young, S., Blanch, K., \& Smith, L. (2015). Beginning teachers as policy workers in Malaysia and New Zealand. International Education Journal: Comparative Perspectives, 14(2), 30-42.

Ansawi, B., \& Pang, V. (2017). The relationship between professional learning community and lesson study: A case study in low performing schools in Sabah, Malaysia. Sains Humanika, 9(13), 63-70. doi: 10.11113/sh.v9n1-3.1144

Bowden, R. (2015). Teacher research in the English language teacher development project. In S. Borg \& H.S. Sanchez (Eds.), International perspectives on teacher research (pp. 152-169). UK: Palgrave Macmillan.

de Vries, S., Jansen, E. P., \& van de Grift, W. J. (2013). Profiling teachers' continuing professional development and the relation with their beliefs about learning and teaching. Teaching and Teacher Education, 33, 78-89. doi: 10.1016/j.tate.2013.02.006

de Figueiredo, E.H.D. (2017). Conceptualizations of English in the discourses of Brazilian language teachers: Issues of mobility, empowerment and international ownership: An analysis of ideologies of English in Brazilian ELT, English Today, 33(2), 31-37. doi: 10.1017/S0266078416000602.

English native speaker programme a success (2015, January 31). Free Malaysia Today. Retrieved from http://www.freemalaysiatoday.com/category/natio $\mathrm{n} / 2015 / 01 / 31 /$ english-native-speaker-programmea-success/ 
Evans, L. (2014). Leadership for professional development and learning: Enhancing our understanding of how teachers develop. Cambridge Journal of Education, 44(2), 179-198. doi: 10.1080/0305764X.2013.860083

Fairclough, N. (1992). Discourse and social change. Cambridge: Polity Press.

Fairclough, N. (2001). Language and power (2nd ed.). Essex: Pearson Education Limited.

Fairclough, N. (2003). Analysing discourse: Textual analysis for social research. London: Routledge.

Gill, S. K. (2012). The complexities of re-reversal of language-in-education policy in Malaysia. In A. Kirkpatrick \& R. Sussex (Eds.), English as an international language in Asia: Implications for language education (pp. 45-61). Netherlands: Springer Netherlands.

Ha, P. L., Kho, J., \& Chng, B. (2013). Nation building, English as an international language, medium of instruction, and language debate: Malaysia and possible ways forward. Journal of International and Comparative Education, 2(2), 58-71. doi: 10.14425/00.50.27

Ha, P. L., \& Que, P. V. (2006). Vietnamese educational morality and the discursive construction of English language teacher identity. Journal of Multicultural Discourses, 1(2), 136-151. doi: 10.2167/md038.0

Halliday, M.A.K. (1985). An introduction to functional grammar. London: Edward Arnold

Hanewald, R. (2016). The impact of English on educational policies and practices in Malaysia. In R. Kirkpatrick (Ed.), English language education policy in Asia (pp. 181-198). Switzerland: Springer International Publishing.

Johnson, D. C. (2015). Intertextuality and language policy. In F.M. Hult \& D.C. Johnson (Eds.), Research methods in language policy and planning: A practical guide (pp.166-180). West Sussex: John Wiley \& Sons.

Kennedy, A. (2005) Models of continuing professional development: A framework for analysis. Journal of In-service Education, 31(2) pp. 235-250.

Labrador, B., Ramón, N., Alaiz-Moretón, H., \& Sanjurjo-González, H. (2014). Rhetorical structure and persuasive language in the subgenre of online advertisements. English for Specific Purposes, 34, 38-47. doi: 10.1016/j.esp.2013.10.002

Ministry of Education Malaysia. (2013). Malaysia education blueprint 2013-2025. Putrajaya:

Ministry of Education Malaysia.

Musa, N. C., Koo, Y. L., \& Azman, H. (2012). Exploring English language learning and teaching in Malaysia. GEMA: Online Journal of Language Studies, 12(1), 35-51.

Nambiar, R. M., \& Thang, S. M. (2016). Examining Malaysian teachers' online blogs for reflective practices: Towards teacher professional development. Language and Education, 30(1), 4357. doi: 10.1080/09500782.2015.1071386

North, B. (2008). The CEFR levels and descriptor scales. In L. Taylor \& C.J. Weir (Eds.), Multilingualism and assessment: Achieving transparency, assuring quality, sustaining diversity - Proceedings of the ALTE Berlin Conference (pp. 21-66). Cambridge: Cambridge University Press.

Patton, K., Parker, M., \& Tannehill, D. (2015). Helping teachers help themselves: Professional development that makes a difference. NASSP Bulletin, 99(1), 26-42. doi: $10.1177 / 0192636515576040$

Sachs, J. (2007). Learning to improve or improving learning: The dilemma of teacher continuing professional development. Proceedings of the 20st Annual World ICSEI Congress, 3-6 January 2007, Convention Center Bernardin Portorož, Slovenia.

Scheibelhofer, P. (2017). It won’t work without ugly pictures: Images of othered masculinities and the legitimisation of restrictive refugee-politics in Austria. NORMA 12(2), 96-111. doi: 10.1080/18902138.2017.1341222

Tan, P. K. (2005). The medium-of-instruction debate in Malaysia: English as a Malaysian language? Language Problems and Language Planning, 29(1), 47-66. doi: 10.1075/lplp.29.1.04tan

Trent, J. (2012). The discursive positioning of teachers: Native-speaking English teachers and educational discourse in Hong Kong. TESOL Quarterly, 46(1), 104-126. doi: 10.1002/tesq.1

Tsui, A. B. M., Shum, M. S.K., Wong, C. K., Tse, S. K., \& Ki, W. W. (1999). Which agenda? Medium of instruction policy in post-1997 Hong Kong. Language Culture and Curriculum 12(3), 196-214. doi: 10.1080/07908319908666578 